\title{
BMJ Open The relationship between leader support, staff influence over decision making, work pressure and patient satisfaction: a cross-sectional analysis of NHS datasets in England
}

\author{
Thomas H R West (D) , ${ }^{1}$ Pascale Daher, ${ }^{2}$ Jeremy F Dawson (D) , ${ }^{3}$ \\ Joanne Lyubovnikova, ${ }^{2}$ Sandra C Buttigieg, ${ }^{4}$ Michael A West ${ }^{5}$
}

To cite: West THR, Daher $P$, Dawson JF, et al. The relationship between leader support, staff influence over decision making, work pressure and patient satisfaction: a cross-sectional analysis of NHS datasets in England. BMJ Open 2022;12:e052778. doi:10.1136/ bmjopen-2021-052778

- Prepublication history for this paper is available online. To view these files, please visit the journal online (http://dx.doi. org/10.1136/bmjopen-2021052778).

Received 27 April 2021 Accepted 25 November 2021

Check for updates

(C) Author(s) (or their employer(s)) 2022. Re-use permitted under CC BY-NC. No commercial re-use. See rights and permissions. Published by BMJ.

For numbered affiliations see end of article.

Correspondence to Dr Thomas H R West; thomas.west@bristol.ac.uk

\section{ABSTRACT}

Objective To explore the relationships between leader support, staff influence over decisions, work pressure and patient satisfaction.

Design A cross-sectional study of large National Health Service (NHS) datasets in England in 2010.

Setting and participants 158 NHS acute hospital trusts in England ( $n=63156$ ) from all staff groups.

Primary and secondary outcome measures Survey data measuring leader support, staff influence over decision making, staff work pressure and objective outcome data measuring patient satisfaction.

Results Multilevel serial mediation analysis showed a significantly positive association between leader support and staff influence over decisions $(B=0.74, S E=0.07$, $p<0.01)$. Furthermore, staff influence over decisions showed a negative association with staff work pressure $(B=-0.84, S E=0.41, p<0.05)$ which in turn was negatively linked to patient satisfaction $(B=-17.50, S E=4.34$, $p<0.01)$. Serial mediation showed a positive indirect effect of leader support on patient satisfaction via staff influence over decisions and work pressure $(B=10.96, S E=5.55$, $p<0.05)$.

Conclusions and implications Our results provide evidence that leader support influences patient satisfaction through shaping staff experience, particularly staff influence over decisions and work pressure. Patients' care is dependent on the health, well-being, and effectiveness of the NHS workforce. That, in turn, is determined by the extent to which leaders are supportive in ensuring that work environments are managed in a way which protects the well-being of staff.

\section{INTRODUCTION}

Patient satisfaction is a key healthcare outcome. ${ }^{1-3}$ In their summary of 55 studies of patient satisfaction, Doyle et $a l^{4}$ found a consistent relationship between patient satisfaction, clinical safety and clinical effectiveness across a range of healthcare settings. Healthcare organisations that focus on improving patient satisfaction have better
Strengths and limitations of this study

- A large-scale, cross-sectional analysis demonstrating how leader support at the organisational level relates to trust-wide patient satisfaction in English National Health Service acute hospitals.

- The design of the study compares survey data with contemporary objective data, mitigating the effects of common source bias.

- A multilevel structural equation modelling approach was taken to identify a serial pathway through which leader support was associated with patient satisfaction; this is a powerful approach which reduces bias from conflation of indirect effects by partitioning lower level variables into latent within and between components.

- The cross-sectional nature of the study does not allow for causal inferences over time.

care quality. ${ }^{56}$ Evidence points to a strong link between staff experience and patient satisfaction. ${ }^{7-9}$ For example, staff job satisfaction and work engagement are positively related to patient satisfaction, and negatively related to hospital mortality rates, infection rates and avoidable errors. ${ }^{7}$ However, while research points to a link between staff experience and patient satisfaction, there is less evidence on whether healthcare leaders influence patient satisfaction, ${ }^{10}$ and if so, to what extent is this due to their shaping the work environment for the workforce. ${ }^{711}$

These questions are particularly salient, as prior to the pandemic at the start of 2020, the National Health Service (NHS) in England was facing the biggest workforce crisis since its creation in 1948. There were over 100000 staff vacancies, representing one in eleven of all posts, ${ }^{12}$ while sickness absence was at $3.4 \%$, twice the rate of the private sector $(1.7 \%) .{ }^{13}$ 
The 2019 NHS English National Staff Survey (NSS) showed that $44 \%$ of nurses and midwives indicated that they had been unwell because of work-related stress in the previous year. Over a quarter of midwives and nurses in secondary care organisations in England reported considering leaving their organisations. ${ }^{14}$ Just under half of doctors in England were considering leaving their organisations $(47 \%)$, while nearly one in five $(17 \%)$ were considering leaving the NHS altogether. ${ }^{15}$ Several factors in the work environment are implicated but two stand out: work pressure ${ }^{16-19}$ and lack of staff influence over decisions. $^{2021}$

Healthcare professionals report high levels of work pressure as a key factor relating to sickness absence, presenteeism and turnover intentions. ${ }^{1422}$ The Nursing and Midwifery Council report that the most common reason, after retirement, for people leaving the nursing register is unmanageable levels of work pressure $(26.4 \%) .{ }^{23}$ Work pressure also affects the quality of care staff feel they are able to deliver. ${ }^{24}$

While staffing levels both contribute to and are a result of work pressure, other working conditions are also important. Specifically, staff refer to lack of voice and influence, and fear and blame cultures. ${ }^{15} 162526$ For example, doctors highlight unacceptable working and training conditions which damage their well-being and effectiveness, and feeling undervalued in the workplace; isolated from seniors, teams and colleagues; unsupported in their roles; fearful of making a mistake and being blamed or prosecuted; overwhelmed by their workloads and, in summary, feeling that they have little control over their work lives. ${ }^{16}$ This is likely to affect the quality of care staff are able to deliver and in turn, patient satisfaction.

Many factors influence staff experience; however, leaders are influential in shaping the work environment by virtue of their hierarchical position, and via their day to day interactions with staff. ${ }^{27}$ To understand the role that leaders play in shaping staff experience, and associated patient experience, we refer to the Job Demands and Resources Model (JD-R), ${ }^{28}{ }^{29}$ which proposes that the experience of work is a result of the combination of work demands placed on staff and the resources available to them to meet those demands. We point to leader support, defined as leadership behaviours that express concern for followers and seek follower input in decision-making and their individual needs, ${ }^{30}{ }^{31}$ as a pivotal resource that buffers the negative impact that job demands (ie, work pressure) have on employees and facilitates the achievement of desired outcomes, and specifically patient satisfaction. ${ }^{72}$ In what follows, we outline the hypothesised relationships between leader support, staff influence over decision making, work pressure and patient satisfaction.

Key characteristics of supportive leaders include giving clear feedback, seeking team member input about decisions that affect their work, caring for the health and wellbeing of followers, and showing appreciation for people's work. These supportive leader behaviours are likely to positively influence the work environment of those they lead, ${ }^{33} 34$ particularly in terms of affording staff greater levels of autonomy, ${ }^{35}$ and consequently increasing their perceptions of influence over decision making. Through empowering staff with increased influence over decision making, supportive leaders are directly enhancing their followers resources, thus increasing their perceived control over their work ${ }^{35} 36$ (H1).

In turn, staff who have influence over decisions about the work environment are able to reduce job demands by eliminating unnecessary activities, and identifying and implementing efficiencies in operations. ${ }^{37}$ Such influence over decisions enables staff to shape processes that directly affect work pressure or workload. Staff influence over decisions is associated with improved outcomes such as climate for innovation, ${ }^{38}$ and better organisational performance, including shorter outpatient waiting times, better care quality and overall hospital/trust performance. ${ }^{39}$ Staff influence over decisions is also likely to act as a psychological buffer against the negative effects of work pressure. Staff who feel able to shape decisions which affect their work are likely to feel a greater sense of control, which is associated with lower stress and higher intrinsic motivation. ${ }^{40}$ Where staff have influence over workloads via their influence over decisions, they are more likely to achieve their work goals, ensuring higher levels of self-efficacy and thereby well-being and job satisfaction. ${ }^{40}{ }^{41}$ Hence, staff influence over decisions is likely to be negatively related to staff work pressure (H2).

Work pressure or overload is a key work demand affecting both staff stress ${ }^{42}$ and intention to quit, ${ }^{43} 44$ and it is linked with levels of patient satisfaction. ${ }^{45}$ This is understandable, as staff under pressure are less likely to have the resources to offer compassionate care, which will in turn reduce patient satisfaction. ${ }^{16}{ }^{17}$ However, staff who enjoy influence over decisions are likely to be better equipped to cope with work pressure because they have more control over their work environment. ${ }^{37}$ It follows that staff who experience less work pressure are likely to deliver better quality care, captured in higher scores of patient satisfaction (H3).

The above line of reasoning implies that staff influence over decisions and work pressure are likely to have a serial mediating role in the relationship between leader support and patient satisfaction (H5), whereby we expect that in organisations with higher levels of leader support, patients will also report higher levels of satisfaction with their care. In sum, previous studies in healthcare highlight associations between leader support and staff experience, ${ }^{18}$ and outcomes such as patient safety. ${ }^{46}$ However, there are few, if any, studies examining relationships between leadership behaviours, staff experience and patient satisfaction, ${ }^{10}$ with the majority of the existing literature focusing on transformational leadership as a theoretical lens to understand leadership in healthcare. ${ }^{10}$ While this is a powerful perspective, questions remain about the specific ways in which leaders can shape the work environment, in order to support staff to deliver high quality care for their patients. In the current study, we aim to contribute to the 
understanding of the relationship between specific leader behaviours and patient satisfaction by examining the role of leader support, staff influence over decisions, work pressure and patient satisfaction. We do this by using a relevant theoretical lens (JD-R) through which we can better understand the mechanisms via which leaders can influence patient satisfaction.

\section{METHODOLOGY}

The annual NSS provides NHS organisations, regulators and the Department of Health with a picture of staff experience. This study used data from the 2010 staff survey, focussing on acute hospitals within England. The response rate was $51 \%$ - a rate considered above the threshold for large-scale studies $(43 \%$ for studies with $>2500$ participants) ${ }^{47} 48$-with responses across all hospital staff, and included data from 158 trusts (out of 167), with 63156 total responses (an average of 400 responses from each organisation). Respondents comprised $35.8 \%$ from nursing, $8.2 \%$ from medical, $31 \%$ from general admin/ management, with the remainder distributed among a range of professions including allied health professionals, scientific/technical and physiotherapy. We selected three specific NSS scales, which we hypothesise play an important role in patient satisfaction: leader support, staff influence over decision making and work pressure. All three underwent rigorous cognitive testing procedure $^{49}$ in their development to ensure content validity, and evidence of their discriminant and predictive validity can be found in previous publications ${ }^{180-52}$ using these scales. Specifically, the leader support and work pressure scales have been part of the staff survey since it first ran in 2003, and were based on some items selected from existing scales, chosen to represent dimensions most relevant to the NHS context. These were then adapted with an extensive cognitive testing procedure, ${ }^{49}$ to ensure relevance, quality and validity. Validity testing for these two scales, including exploratory and confirmatory factor analysis (CFA) to demonstrate discriminant validity, was conducted and published as part of the first NHS staff survey, ${ }^{51}$ as well as further CFA appearing in this manuscript. The staff influence over decision-making scale was not introduced until 2009, but it had similar origins, and was also subject to extensive cognitive testing. Validity data for this scale were published as part of the 'NHS Staff Management and Health Service Quality' report published by the Department of Health. ${ }^{18}$

Items comprising the scales were measured using 5-point Likert ratings ranging from 1 (strongly disagree) to 5 (strongly agree) and a mean score was calculated. All scales demonstrated good reliability. The leader support scale $(\alpha=0.92)$ assesses staff ratings of their immediate managers in terms of the level of support, guidance and feedback he or she provides and the extent to which the leader seeks their opinion before making decisions which affect their work. The scale items are '(My immediate manager...) encourages those who work for her/him to work as a team; can be counted on to help me with a difficult task at work; gives me clear feedback on my work; asks for my opinion before making decisions that affect my work; and, is supportive in a personal crisis'. The staff influence over decisions scale $(\alpha=0.86)$ assesses the extent to which staff reported being able to contribute to decisions which influence their work. The scale items are 'I am able to make suggestions to improve the work of my team/department; there are frequent opportunities for me to show initiative in my role; and, I am able to make improvements happen in my area of work'. The work pressure scale $(\alpha=0.72)$ assesses the extent to which staff have a workload that is more than they can cope with and includes the extent to which staff feel there is a lack of time or resources to do their job well. The scale items are 'I cannot meet all the conflicting demands on my time at work; there are enough staff at this trust for me to do my job properly; I have adequate materials, supplies and equipment to do my work; I do not have time to carry out all my work'. Two items, 'there are enough staff at this trust for me to do my job properly; I have adequate materials, supplies and equipment to do my work' were reverse coded, whereby higher scores indicated higher levels of work pressure.

Patient satisfaction was assessed using data from the NHS acute inpatient survey, 2010. The methodology for determining this score replicated the approach used by Dawson. ${ }^{11}$ The survey contained the item 'overall, how would you rate the care you received' and asked adult inpatients to rate this on a scale of $1-5$ (poor to excellent). This was converted to a scale of $0-100$ (eg, $1=0,5=100)$, after which a mean score was calculated and averaged to the organisational (trust) level. In 2010 the average score for inpatient experience was 77.7 with scores ranging from 66.7 to 92.6 .

\section{Patient and public involvement statement}

Our research used data from the NHS NSS and Adult Inpatient Survey in 2010. Secondary data analysis was included in the ethical approval, which was awarded by the North West MREC, approval number 03/8/047.

As our research used secondary data, there was no direct patient involvement. However, patient satisfaction data was used, thus the research is centrally informed by patient priorities, experiences and preferences.

\section{Statistical analysis}

The data were analysed using multilevel structural equation modelling (MSEM) ${ }^{53} 54$ in Mplus V.8. ${ }^{55}$ MSEM safeguards against conflation of effects by partitioning lower level variables into latent within and between components. Accordingly, MSEM decomposes the variance of level 1 (individual/staff) variables into within and between components, accounting for the fact that relationships may differ between the level 1 (individual/staff) and level 2 (trust) levels. ${ }^{53}$ The data used here are observable (raw) scores, so explicit centring of variables was not required in the analysis. ${ }^{53}$ 
A multilevel serial mediation model was employed in which the level 1 (individual/staff level) variables (leader support, staff influence over decision making and work pressure) were modelled at level 1 and level 2 simultaneously; patient satisfaction was modelled at level 2. A random intercept and fixed slope model was specified and MSEM was applied to test the serial mediation effect of leader support on patient satisfaction via staff influence over decision making and work pressure. Missing values were handled using full information maximum likelihood to ensure all data points were used in an unbiased way. ${ }^{56}$

In the analysis, we controlled for trust size (number of staff), the ratio of doctors to beds as they have been shown to influence patient satisfaction ${ }^{57}$ and whether the trust was London based (dummy coded: $0=$ not in London, 1=London-based) given established higher levels of patient satisfaction in London trusts. ${ }^{58}$

CFAs were conducted using Mplus V. $8^{55}$ to establish the independence of the predictor and mediating variables (leader support, staff influence over decisions, work pressure). We subjected the items to (1) an 11-item one-factor model which suggests a single undifferentiated factor, (2) a two-factor model where we assigned the five leader support items to load on one factor and the remaining six items to load on another factor and (3) a three-factor model where the 11 items were assigned to load on their respective factors (leader support, staff influence over decisions and work pressure). Model fit was estimated using indices recommended by $\mathrm{Hu}$ and Bentler. ${ }^{59}$ We also used $\chi^{2}$ difference tests to compare the different models by examining differences in $\chi^{2}$ per degree of freedom. Results show that the hypothesised three-factor model consisting of leader support, staff influence over decisions and work pressure, demonstrated the best fit to the data $\left(\chi^{2}(41)=37280.33, \mathrm{p}<0.001\right.$, comparative fit index $(\mathrm{CFI})=0.96$, Tucker-Lewis index $(\mathrm{TLI})=0.94$, root mean square error of approximation (RMSEA) $=0.07$, standardised root mean squared residual $(\mathrm{SRMR})=0.06$; two-factor model: $\chi^{2}(43)=160123.92, \mathrm{p}<0.001, \mathrm{CFI}=0.82$, TLI $=0.77, \quad$ RMSEA $=0.15, \quad$ SRMR $=0.11 ; \quad$ one-factor model: $\chi^{2}(44)=214415.17, \mathrm{p}<0.001$, CFI $=0.76$, TLI $=0.7$, RMSEA $=0.17, \mathrm{SRMR}=0.12$ ). All items loaded highly on their respective factors, with scores ranging from 0.37 to 0.89 . In addition, the $\chi^{2}$ difference test showed that the three-factor model had a significantly better fit than the two-factor model $(\Delta \chi 2 / \Delta \mathrm{df}=122843.58 / 2, \mathrm{p}<0.001)$ and the one-factor model $(\Delta \chi 2 / \Delta \mathrm{df}=177134.83 / 3, \mathrm{p}<0.001)$.

\section{RESULTS}

Table 1 displays the means, SD and intercorrelations of study variables. A moderate and positive correlation is found between leader support and staff influence over decisions $(\mathrm{r}=0.51, \mathrm{p}<0.01)$ and a moderate and negative correlation between leader support and work pressure $(\mathrm{r}=-0.27, \mathrm{p}<0.01)$. A negative correlation is observed between staff influence over decisions and work pressure $(\mathrm{r}=-0.21, \mathrm{p}<0.01)$.

MSEM results are presented in table 2 and show that leader support is significantly and positively related to staff influence over decisions $(\mathrm{B}=0.74, \mathrm{SE}=0.07, \mathrm{p}<0.01)$. In turn, staff influence over decisions is significantly and negatively related to work pressure $(\mathrm{B}=-0.84, \mathrm{SE}=0.41$, $\mathrm{p}<0.05)$ and work pressure is significant and negatively related to patient satisfaction $(\mathrm{B}=-17.50, \mathrm{SE}=4.34$, $\mathrm{p}<0.01$ ), supporting hypotheses $1-3$. Results of the serial mediation hypothesis show that leader support has a positive effect on patient satisfaction via staff influence over decisions and work pressure $(\mathrm{B}=10.96, \mathrm{SE}=5.55, \mathrm{p}<0.05)$. Figure 1 displays the SEM model with the estimated results of the hypothesised relationships.

\section{DISCUSSION}

Building on the JD-R model, ${ }^{29} 60$ this study explored the relationship between leader support and patient

\begin{tabular}{|c|c|c|c|c|c|c|c|c|}
\hline & Type & Range & M & SD & 1 & 2 & 3 & 4 \\
\hline \multicolumn{9}{|l|}{ Level 2 (trust level) } \\
\hline 2. London based $\ddagger$ & Binary & 1 & 0.17 & 0.37 & -0.05 & - & & \\
\hline 3. Ratio of doctors/bed & Ratio & 1.58 & 0.75 & 0.23 & $.19^{\star \star}$ & $.50^{\star \star}$ & - & \\
\hline Level 1 (Individual/staff level) & Type & Range & M & SD & 5 & 6 & 7 & - \\
\hline 5. Leader support & Scale & 4 & 3.61 & 0.94 & - & & & \\
\hline 6. Staff influence over decisions & Scale & 4 & 3.55 & 0.80 & $0.51^{\star \star}$ & - & & \\
\hline 7. Work pressure & Scale & 4 & 3.10 & 0.81 & $-0.27^{\star *}$ & $-0.21^{\star \star}$ & - & \\
\hline
\end{tabular}

$\mathrm{N}$ level 2=158; $\mathrm{n}$ level $1=63156$.

${ }^{* *} \mathrm{P}<0.01$.

†Trust size is total number of employees divided by 10 .

$\neq 0$ = not in London; 1=London based. 
Table 2 Results of multilevel serial mediation of leader support on patient satisfaction via staff influence over decisions and work pressure

\begin{tabular}{|c|c|c|c|c|c|c|c|c|c|}
\hline \multirow[b]{2}{*}{ Variables } & \multicolumn{3}{|c|}{$\begin{array}{l}\text { Staff influence over } \\
\text { decisions }\end{array}$} & \multicolumn{3}{|c|}{ Work pressure } & \multicolumn{3}{|c|}{ Patient satisfaction } \\
\hline & B & SE & $P$ value & B & SE & $P$ value & B & SE & $P$ value \\
\hline Leader support & 0.43 & 0.00 & 0.00 & -0.18 & 0.00 & 0.00 & - & - & - \\
\hline $\begin{array}{l}\text { Staff influence over } \\
\text { decisions }\end{array}$ & - & - & - & -0.09 & 0.00 & 0.00 & - & - & - \\
\hline \multicolumn{10}{|c|}{ Level 2 (trust level) effects } \\
\hline Trust size ${ }^{*}$ & 0.00 & 0.00 & 0.08 & 0.00 & 0.00 & 0.44 & -0.02 & 0.01 & 0.14 \\
\hline London based $†$ & 0.01 & 0.01 & 0.37 & -0.01 & 0.02 & 0.53 & -7.06 & 0.96 & 0.00 \\
\hline Ratio of doctors/bed & 0.07 & 0.02 & 0.00 & 0.02 & 0.05 & 0.74 & 6.14 & 2.03 & 0.00 \\
\hline Work pressure & & & & & Effect & & SE & $P$ value & \\
\hline \multicolumn{10}{|l|}{ Patient satisfaction } \\
\hline \multicolumn{5}{|c|}{ Indirect effect via staff influence over decisions } & 19.89 & & 13.46 & 0.14 & \\
\hline \multicolumn{4}{|c|}{ Indirect effect of via work pressure } & & 2.88 & & 6.40 & 0.65 & \\
\hline \multicolumn{5}{|c|}{ Serial indirect effect via staff influence over decisions and work pressure } & 10.96 & & 5.55 & 0.04 & \\
\hline
\end{tabular}

$\mathrm{n}=63156$ at the Level 1 and 158 at level 2.

*Trust size is total number of employees divided by 10 .

†0 $=$ not in London; $1=$ London based.

satisfaction via a serial mediation model of influence over decisions and work pressure in the acute sector of the English NHS. The research found a positive and significant relationship between ratings of leader support and levels of patient satisfaction, and found that this relationship operated via staff influence over decisions and work pressure. The research suggests that where trusts have more supportive leaders, patient satisfaction is higher. These findings are in line with predictions derived from the JD-R model, ${ }^{28} 61$ and suggest that supportive leadership behaviours equip staff with the resources they need to cope with work demands, as well as empowering them to make informed decisions consistent with organisational purposes, ${ }^{62}$ ultimately enhancing staff satisfaction and enabling them to deliver higher quality care to patients. ${ }^{63}$ Additionally, the research suggests that staff influence over decisions is a key resource, in terms of autonomy and subsequent shaping of the work environment. As a

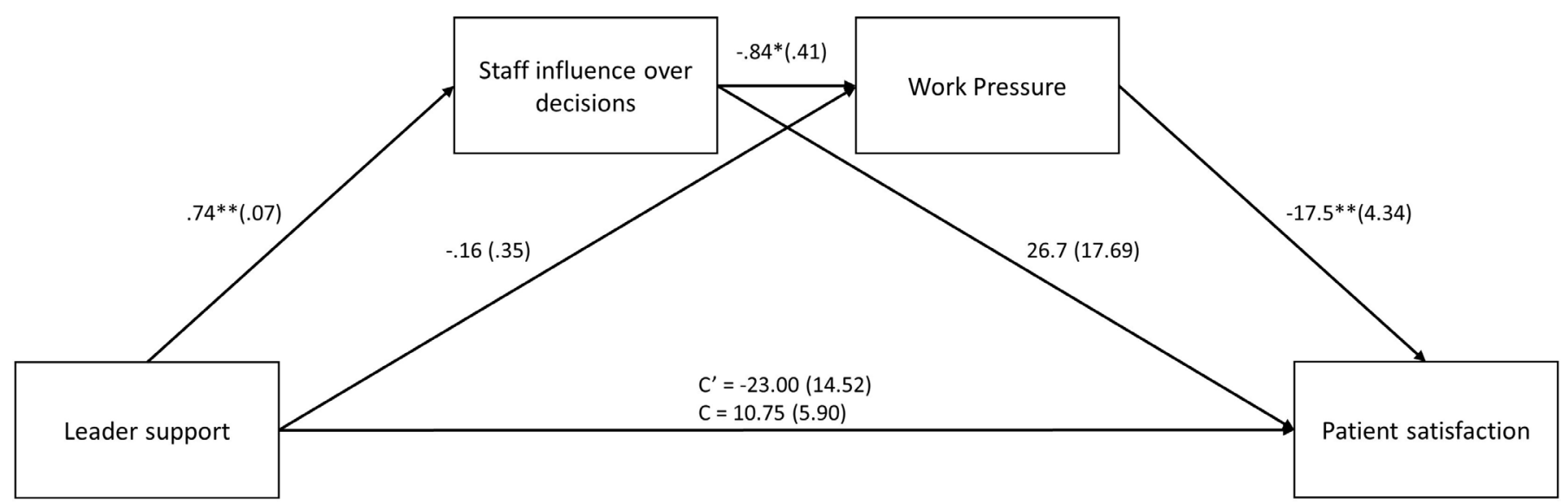

Figure 1 Serial mediation model. Non-standardised coefficients are shown with SEs in parentheses. Level $1 \mathrm{n}=63156$; level $2 n=158 .{ }^{*} \mathrm{P}<0.05 ;{ }^{* *} \mathrm{p}<0.001$. 
result, they are able to respond to the demands of their work (pressures) by taking actions to objectively manage their work tasks or environment more effectively, as well as feeling a greater level of psychological control and autonomy to do so. Finally, the research indicates that the level of work pressure staff experience is linked with patient satisfaction. The findings have important practical implications, given that high work pressure is likely to damage staff well-being and care quality, and thus have a detrimental effect on patient satisfaction.

Our research addresses several important issues. First, our research provides quantitative evidence that leadership behaviour can be explicitly linked with organisational outcomes. While this relationship appears intuitive, there is scant evidence establishing empirical associations between specific leadership behaviours and objective, organisational level outcomes. ${ }^{10}$ Additionally, by conducting multilevel analysis, we were able to account for variance at the individual level (eg, individual practices endorsed by leaders) and show how leader practices at the trust level are conducive for good patient outcomes. While the influence of individual leader support is important for employee experience, ${ }^{27}$ the nature of our multilevel analysis suggests that the relationship between leader support and patient satisfaction operates at the trust level. This can be conceptualised as a general organisational ethos of supportive leadership, and that this is positively linked with patient satisfaction. This chimes with recent research highlighting the importance of organisational culture and climate for staff influence over decisions, and workload factors in relation to COVID-19, for example. ${ }^{64}$ We did not specifically test for organisational climate, and thus future research might examine the effects of leadership behaviours on climate and culture and their trickle-down influence on staff experience and patient outcomes.

Interestingly, when examining the findings further, we found that the link between leader support and patient satisfaction using each mediating variable alone was nonsignificant. The indirect effect was only significant when following a serial pathway. As described above, the results suggest leader support is associated with staff influence over decisions, consequent levels of work pressure, and in turn, patient satisfaction. However, individually, neither staff influence over decisions nor work pressure is sufficient to associate leader support with patient satisfaction. It is only the combination of factors which shows a link with patient satisfaction. In interpreting this finding, a plausible explanation is that leader support is influential in a number of areas, and therefore, operates in a several ways to influence the work environment and provide staff with helpful resources, including staff influence over decisions, which culminates in high-quality care. This finding may be timely, given that the COVID-19 pandemic has led to dramatic levels of work pressure across the healthcare industry. ${ }^{656}$ It would be prudent for future research to also examine the extent to which the model presented here holds during times of crisis.
Our study focused on a specific aspect of leadership, namely leader support, and demonstrated how this relates to the work environment and patient satisfaction. Indeed, an advantage of our approach is that by using the JD-R model to outline distinct relationships between specific leadership behaviours and associated factors, we respond to recent calls to move away from problematic multidimensional leadership theories. ${ }^{67-69}$ Instead, we provide evidence which may help to guide the theoretical 'rebuilding' of traditional leadership theories, as well as offer clear, practical guidance for practitioners. The multitude of leadership research demonstrates that other facets of leadership, for example leader fairness ${ }^{70}$ or leader-follower value congruence, ${ }^{71}$ will relate to the work environment and across a range of outcomes. Future investigations could explore these specific relationships, highlighting important avenues for future research in healthcare leadership.

It is also important to acknowledge the limitations of this research. While the data analytic strategy employed MSEM which analyses the pathway from leader support to patient satisfaction, the cross-sectional design limits the extent to which causality can be inferred. Although there is support for the theoretical predictions of the model, longitudinal data is required to eliminate reverse causality explanations. For example, it is possible that staff competence or attitudes may influence leader behaviours. Additionally, the NSS uses self-reported data and therefore the predictors and mediators are subject to common method variance, and are consequently vulnerable to inflated relationships. ${ }^{72}$ In order to limit these effects, the use of independent source organisational outcome data (patient satisfaction) is a methodological strength. Furthermore, although the response rate of $51 \%$ is slightly lower than the average rate for healthcare professionals (average response rate $=53 \%{ }^{48}$ ) it is well within acceptable margins (43\%) for large-scale surveys, ${ }^{47}$ and any response bias is likely to be minimal. ${ }^{73}$ Nevertheless, given the response rate, it is important to recognise the potential for some response bias remains. Similarly, our sample was confined to acute NHS trusts in England, and comprised of $35.8 \%$ nursing, $8.2 \%$ medical, $31 \%$ from general admin/management, with the remainder distributed across a range of professions. The latest NHS workforce statistics indicate that our sample is broadly in-line with the workforce distribution, though nursing is slightly over-represented. ${ }^{74}$ Thus, while our findings are theoretically applicable across a range of healthcare contexts and cohorts, the context and distribution of our sample, should be taken when considering generalisability of the findings. Finally, our data are from 2010, and while the landscape of the NHS will have changed since then, there is no reason to assume that the nature of the relationships examined will be different. Indeed, our findings still provide important lessons for NHS leaders and staff now and in the future.

The current workforce crisis in the NHS which predates, but has been exacerbated by the pandemic, requires 
supportive leadership that ensures clear direction for the future with a focus on meeting staff and patients' needs. Such support is directly contingent on the extent to which leaders behave in ways which enable staff to have their needs for autonomy and control met, which, in turn, directly affects the quality of care experienced by patients. Learning and acting on this research evidence is vital for sustaining health services in the context of the workforce challenges described. High quality, continually improving and compassionate care for patients, is dependent on supportive leadership, which lays the foundation for high quality, continually improving and compassionate support for staff. Thus, our findings are timely and important, offering guidance for healthcare organisations focused on improving the experience of the staff, and their patients. These findings have clear implications for healthcare leaders at all levels, as well as for leadership development approaches.

\section{Author affiliations}

${ }^{1}$ Operations and Management Science, Innovation \& Healthcare, University of Bristol, Bristol, UK

${ }^{2}$ University of Liverpool Management School, University of Liverpool, Liverpool, UK

${ }^{3}$ Sheffield University Management School, University of Sheffield, Sheffield, UK

${ }^{4}$ Health Systems Management \& Leadership, University of Malta, Msida, Malta

${ }^{5}$ Lancaster University Management School, Lancaster University, Lancaster, UK

\section{Twitter Jeremy F Dawson @jfdawson76 and Michael A West @westm61}

Contributors THRW designed the approach and wrote the manuscript. PD conducted the analysis. JD provided statistical expertise, JL and SB provided topic expertise and conceptual oversight. MW provided topic expertise and editorial review. THRW is the guarantor and accepts full responsibility for the finished work and the conduct of the study, had access to the data, and controlled the decision to publish.

Funding The authors have not declared a specific grant for this research from any funding agency in the public, commercial or not-for-profit sectors.

Competing interests None declared.

Patient and public involvement Patients and/or the public were not involved in the design, or conduct, or reporting, or dissemination plans of this research.

Patient consent for publication Not applicable.

Ethics approval Data used were from the NHS National Staff Survey and Adult Inpatient Survey in 2010. Secondary data analysis was included in the ethical approval, which was awarded by the North West MREC, approval number 03/8/047.

Provenance and peer review Not commissioned; externally peer reviewed.

Data availability statement Data may be obtained from a third party and are not publicly available. NHS Inpatient Data are publicly available via the UK Data Service. NHS staff survey data are publicly available via the Survey Coordination Centre, Picker Institute while the individual level data are available upon reasonable request.

Open access This is an open access article distributed in accordance with the Creative Commons Attribution Non Commercial (CC BY-NC 4.0) license, which permits others to distribute, remix, adapt, build upon this work non-commercially, and license their derivative works on different terms, provided the original work is properly cited, appropriate credit is given, any changes made indicated, and the use is non-commercial. See: http://creativecommons.org/licenses/by-nc/4.0/.

ORCID iDs

Thomas H R West http://orcid.org/0000-0002-9782-0691

Jeremy F Dawson http://orcid.org/0000-0002-9365-8586

\section{REFERENCES}

1 Secretary of State for Health. High quality care for all: NHS next stage review final report. The Stationery Office, 2008.

2 Gleeson H, Calderon A, Swami V, et al. Systematic review of approaches to using patient experience data for quality improvement in healthcare settings. BMJ Open 2016;6:e011907.

3 Graham C, Käsbauer S, Cooper R, et al. An evaluation of a near real-time survey for improving patients' experiences of the relational aspects of care: a mixed-methods evaluation. Health Serv Deliv Res 2018;6:1-174.

4 Doyle C, Lennox L, Bell D. A systematic review of evidence on the links between patient experience and clinical safety and effectiveness. BMJ Open 2013;3:e001570.

5 Luxford K, Safran DG, Delbanco T. Promoting patient-centered care: a qualitative study of facilitators and barriers in healthcare organizations with a reputation for improving the patient experience. Int J Qual Health Care 2011;23:510-5.

6 Hibbard JH, Greene J. What the evidence shows about patient activation: better health outcomes and care experiences; fewer data on costs. Health Aff 2013;32:207-14.

7 Dawson J. Links between NHS staff experience and patient satisfaction: analysis of surveys from 2014 and 2015. NHS England, 2018. Available: https://www.england.nhs.uk/wp-content/ uploads/2018/02/links-between-nhs-staff-experience-and-patientsatisfaction-1.pdf

8 Sizmur S, Raleigh V. The risks to care quality and staff wellbeing of an NHS system under pressure. The King's Fund, 2018.

9 Maben J, Adams M, Peccei R, et al. 'Poppets and parcels': the links between staff experience of work and acutely ill older peoples' experience of hospital care. Int J Older People Nurs 2012;7:83-94.

10 West MA, Armit K, Loewenthal L. Leadership and leadership development in health care: the evidence base. The King's Fund, 2015.

11 Dawson J. Does the experience of staff working in the NHS link to the patient experience of care? an analysis of links between the 2007 acute trust inpatient and NHS staff surveys. Institute for Health Services Effectiveness, 2009.

12 Beech J, Bottery S, Charlesworth A. Closing the gap. London, 2019.

13 Office for National Statistics. Sickness absence falls to the lowest rate on record. Available: https://www.ons.gov.uk/employmentandlab ourmarket/peopleinwork/employmentandemployeetypes/articles/sick nessabsencefallstothelowestratein24years/2018-07-30 [Accessed 8 Apr 2021].

14 NHS England. Nhs staff survey 2019: national results briefing. survey coordination centre, 2020.

15 NHS England. National NHS staff survey 2018, 2018.

16 West M, Coia D, et al. Caring for doctors, caring for patients. How to transform UK healthcare environments to support doctors and medical students to care for patients. London, 2019. https://www. gmc-uk.org/about/how-we-work/corporate-strategy-plans-andimpact/supporting-a-profession-under-pressure/uk-wide-review-ofdoctors-and-medical-students-wellbeing\%0Ahttps://www.gmc-uk. $\mathrm{org} /$-/media/documents/caring-for-doctors-caring-for-patients_

17 West M, Bailey S, Williams E. The courage of compassion supporting nurses and midwives to deliver high-quality care. London, 2020. https://www.kingsfund.org.uk/sites/default/files/2020-09/The courage of compassion summary_web_0.pdf

18 West MA, Dawson JF, Admasachew L. Nhs staff management and health service quality: results from the NHS staff survey and related data, 2011. Available: https://www.gov.uk/government/publications/ nhs-staff-management-and-health-service-quality

19 Wall TD, Bolden RI, Borrill CS, et al. Minor psychiatric disorder in NHS trust staff: occupational and gender differences. Br J Psychiatry 1997;171:519-23.

20 West MA, Dawson JF. Employee engagement and NHS performance. London: The King's Fund, 2012.

21 Dawson J, West M. Employee engagement, sickness absence and agency spend in NHS trusts. NHS Engl 2018 https://www.england. nhs.uk/publication/employee-engagement-sickness-absence-andagency-spend-in-nhs-trusts

22 Mcllroy R. Royal College of nursing employment survey, 2019. Available: https://www.rcn.org.uk/professional-development/ publications/pub-007927

23 Nursing and Midwifery Council. Leavers' survey 2019: why do people leave the NMC register? 2020. Available: https://www.nmc.org.uk/ globalassets/sitedocuments/nmc-register/march-2020/nmc-leaverssurvey-2019.pdf

24 Royal College of Midwives. Why Midwives Leave - revisited. London, 2016. https://cdn.ps.emap.com/wp-content/uploads/sites/3/2016/ 10/Why-Midwives-Leave.pdf 
25 NHS Wales. NHS wales staff survey 2018: National report [online], 2018. Available: http://www.wales.nhs.uk/sitesplus/documents/866/ 4.3b National Staff Survey Report.pdf

26 Department of Health. 2015 HSCNI staff survey: regional report [online], 2016. Available: https://www.health-ni.gov.uk/sites/default/ files/publications/health/staff-survey-regional-report.pdf

27 Avolio BJ, Walumbwa FO, Weber TJ. Leadership: current theories, research, and future directions. Annu Rev Psychol 2009;60:421-49.

28 Demerouti E, Bakker AB, de Jonge J, et al. Burnout and engagement at work as a function of demands and control. Scand J Work Environ Health 2001;27:279-86.

29 Bakker AB, Demerouti E. The job Demands-Resources model: state of the art. J Manag Psychol 2007;22:309-28.

30 Rafferty AE, Griffin MA. Dimensions of transformational leadership: conceptual and empirical extensions. Leadersh Q 2004:15:329-54.

31 Arnold JA, Arad S, Rhoades JA, et al. The empowering leadership questionnaire: the construction and validation of a new scale for measuring leader behaviors. J Organ Behav 2000;21:249-69.

32 Borrill C, West M, Carter M. The relationship between staff satisfaction and patient satisfaction: results from Wolverhampton hospitals NHS trust. Available: https://www.england.nhs.uk/wpcontent/uploads/2018/06/01-018-edc03-staff-inpatient-surveyreport.pdf [Accessed 11 Mar 2021].

33 Hobman EV, Jackson CJ, Jimmieson NL, et al. The effects of transformational leadership behaviours on follower outcomes: an identity-based analysis. Eur J Work Organ Psychol 2011;20:553-80.

34 Rooney JA, Gottlieb BH, Newby-Clark IR. How support-related managerial behaviors influence employees. J Manag Psychol 2009:24:410-27.

35 Breevaart K, Bakker A, Hetland J, et al. Daily transactional and transformational leadership and daily employee engagement. J Occup Organ Psychol 2014;87:138-57.

36 Tims M, Bakker AB. Job crafting: towards a new model of individual job redesign. SA J Ind Psychol 2010;36:1-9.

37 Tjosvold D. Making employee involvement work: cooperative goals and controversy to reduce costs. Human Relations 1998;51:201-14.

38 Wallace JC, Butts MM, Johnson PD, et al. A multilevel model of employee innovation. J Manage 2016;42:982-1004.

39 Bosak J, Dawson J, Flood P, et al. Employee involvement climate and climate strength. J Organ Eff People Perform 2017;4:18-38.

40 Ryan RM, Deci EL. Self-determination theory and the facilitation of intrinsic motivation, social development, and well-being. Am Psychol 2000;55:68-78

41 Lawler EE. High-involvement management: participative strategies for improving organizational performance. San Francisco: Jossey-Bass, 1986.

42 Bakker AB. A job demands-resources approach to public service motivation. Public Adm Rev 2015;75:723-32.

43 Jourdain G, Chênevert D. Job demands-resources, burnout and intention to leave the nursing profession: a questionnaire survey. Int $J$ Nurs Stud 2010;47:709-22.

44 Fletcher L, Carter M, Lyubovnikova J. Congruency of resources and demands and their effects on staff turnover within the English health care sector. J Occup Organ Psychol 2018;91:688-96.

45 Goh ML, Ang ENK, Chan Y-H, et al. Patient satisfaction is linked to nursing workload in a Singapore Hospital. Clin Nurs Res 2018;27:692-713.

46 McFadden KL, Henagan SC, Gowen CR. The patient safety chain: Transformational leadership's effect on patient safety culture, initiatives, and outcomes. J Oper Manag 2009;27:390-404.

47 Cook JV, Dickinson HO, Eccles MP. Response rates in postal surveys of healthcare professionals between 1996 and 2005: an observational study. BMC Health Serv Res 2009;9:160.

48 Cho Yl, Johnson TP, VanGeest JB. Enhancing surveys of health care professionals. Eval Health Prof 2013;36:382-407.

49 Jobe JB, Mingay DJ. Cognitive research improves questionnaires. Am J Public Health 1989;79:1053-5.

50 Bilotta I, Dawson JF, King EB. The role of fairness perceptions in patient and employee health: a multilevel, multisource investigation. J Appl Psychol 2021
51 Healthcare Commission. 2003 NHS staff survey. London, 2004.

52 Powell M, Dawson J, Topakas A, et al. Staff satisfaction and organisational performance: evidence from a longitudinal secondary analysis of the NHS staff survey and outcome data. Heal Serv Deliv Res 2014;2:1-306.

53 Preacher KJ, Zyphur MJ, Zhang Z. A general multilevel SEM framework for assessing multilevel mediation. Psychol Methods 2010;15:209-33.

54 Preacher KJ, Zhang Z, Zyphur MJ. Multilevel structural equation models for assessing moderation within and across levels of analysis. Psychol Methods 2016;21:189-205.

55 Muthén LK, Muthén BO. Mplus user's guide. 6th edn. Los Angeles, CA: Muthén \& Muthén, 2017.

56 Enders C, Bandalos D. The relative performance of full information maximum likelihood estimation for missing data in structural equation models. Struct Equ Model A Multidiscip J 2001;8:430-57.

57 Bernerth JB, Aguinis H. A critical review and best-practice recommendations for control variable usage. Pers Psychol 2016;69:229-83.

58 King EB, Dawson JF, West MA, et al. Why organizational and community diversity matter: representativeness and the emergence of Incivility and organizational performance. Acad Manag $J$ 2011;54:1103-18.

$59 \mathrm{Hu}$ Li-tze, Bentler PM. Cutoff criteria for fit indexes in covariance structure analysis: conventional criteria versus new alternatives. Struct Equ Model A Multidiscip J 1999;6:1-55.

60 Demerouti E, Bakker AB, Nachreiner F, et al. The job demandsresources model of burnout. J Appl Psychol 2001;86:499-512.

61 Schaufeli WB, Bakker AB. Job demands, job resources, and their relationship with burnout and engagement: a multi-sample study. J Organ Behav 2004;25:293-315.

62 Richardson HA, Vandenberg RJ. Integrating managerial perceptions and transformational leadership into a work-unit level model of employee involvement. J Organ Behav 2005;26:561-89.

63 Räikkönen O, Perälä M-L, Kahanpää A. Staffing adequacy, supervisory support and quality of care in long-term care settings: staff perceptions. J Adv Nurs 2007;60:615-26.

64 National Academies of Sciences Engineering and Medicine 2019. Taking action against clinician burnout. Washington, DC: National Academies Press, 2019.

65 lacobucci G. Covid-19: doctors feel under pressure to work extra shifts unpaid, survey shows. BMJ 2021;373:n1189.

66 Mira JJ, Carrillo I, Guilabert M, et al. Acute stress of the healthcare workforce during the COVID-19 pandemic evolution: a crosssectional study in Spain. BMJ Open 2020;10:e042555.

67 van Knippenberg D, Sitkin SB. A critical assessment of charismatictransformational leadership research: back to the drawing board? ANNALS 2013;7:1-60.

68 Gottfredson RK, Wright SL, Heaphy ED. A critique of the LeaderMember exchange construct: back to square one. Leadersh $Q$ 2020;31:101385.

69 Alvesson M, Einola K. Warning for excessive positivity: authentic leadership and other traps in leadership studies. Leadersh $Q$ 2019:30:383-95.

70 van Knippenberg D, De Cremer D, van Knippenberg B. Leadership and fairness: the state of the art. Eur J Work Organ Psychol 2007:16:113-40.

71 Jiménez P, Winkler B, Dunkl A. Creating a healthy working environment with leadership: the concept of health-promoting leadership. Int J Hum Resour Manag 2017;28:2430-48.

72 Podsakoff PM, MacKenzie SB, Lee J-Y, et al. Common method biases in behavioral research: a critical review of the literature and recommended remedies. J Appl Psychol 2003;88:879-903.

73 Cull WL, O'Connor KG, Sharp S, et al. Response rates and response bias for 50 surveys of pediatricians. Health Serv Res 2005;40:213-26.

74 Department of Health. NHS workforce statistics - July 2021, 2021. Available: https://digital.nhs.uk/data-and-information/publications/ statistical/nhs-workforce-statistics/july-2021 